\title{
Does atopy have any predictive value for laboratory animal allergy? A comparison of different concepts of atopy
}

\author{
A J M SLOVAK, R N HILL \\ From Fisons Occupational Health Service, Loughborough, Leicestershire LE11 0BB, UK
}

\begin{abstract}
Atopy is widely used as a discriminant in selection for employment involving exposure to allergenic substances. The validity of this has been tested in a population with a known burden of what is largely considered to be an IgE mediated disease, laboratory animal allergy. The findings suggest that atopy is insufficiently sensitive and specific for this purpose and that this is probably true for other occupational allergic diseases. The relation between different concepts of atopynamely, atopy defined by family history, by personal history, and by skin prick tests with common allergens-has also been examined. The subpopulations identified by these criteria differed appreciably. Different concepts of atopy should not be used synonymously as they often are at present.
\end{abstract}

Atopy is a useful and widespread concept in clinical medicine describing a tendency to develop allergic disease. In occupational medicine it has traditionally been used as a discriminant in selecting those who are to work with substances capable of causing allergic disorders. Several studies have sought to assess the importance of atopy as a marker of susceptibility to disease, usually by using skin prick tests as the criterion of atopy. ${ }^{1-7}$ In clinical practice, however, it is still much more common to use family or personal history as indicators of atopy. Thus at least three different concepts of atopy have evolved. To assess their value as discriminants, we have studied the sensitivity, specificity, predictive value, and correlation of these different concepts in a population with a known burden of an IgE mediated, occupational allergic disease-laboratory animal allergy. Our findings were derived from data generated in our cross sectional study of laboratory animal allergy (LAA) ${ }^{5}$ but not previously analysed.

\section{Methods}

In an exposed population of 146 individuals, surveyed to assess the prevalence of laboratory animal allergy, a standardised questionnaire was developed and used to obtain evidence of family history (parents, grandparents, siblings) and personal history of allergy. The questionnaire was administered by one nurse inter-

Accepted 19 May 1986 viewer. Family and personal history of allergy were accepted as positive if such had been diagnosed at any time by a clinician, although not necessarily confirmed by objective tests. It is easy to criticise this definition but looser definitions are commonplace as discriminants in occupational health practice. Tighter definitions, especially those requiring objective confirmation, would have seriously underestimated the true rates.

Standard skin prick tests to grass mixture, house dust, and Aspergillus (Bencard) were also carried out, atopy being defined as the presence of a $3 \mathrm{~mm}$ weal to any one of the three tests after 10 minutes. ${ }^{5}$ Skin tests for cat, dog, and horse hair were also performed but not included as criteria for atopy because of the possibility of cross reactivity with LAA antigens. The standardised questionnaire was used in an attempt to minimise ascertainment bias, a fault to which this type of study is prone. Memory bias is more difficult to avoid but this population was in secure employment and was not to be the subject of any discriminatory action were atopy to be found. Additionally, previously presented evidence suggested that there was no preferential wastage of atopic individuals from the population studied. ${ }^{5} \mathrm{~A}$ diagnosis of LAA was made solely on the symptoms reported by patients. The questionnaire was so designed that it was necessary for patients to ascribe their symptoms positively to their work and then identify the species of animals which had caused the effect before the diagnosis was accepted. The subjects 
were divided into three groups according to their symptoms. The first group consisted of those who had LAA asthma (with rhinitis). All but two of these had positive skin prick tests to specific animal antigens (rat, mouse, guinea pig, rabbit), indicating IgE mediated disease. The second group comprised people with LAA rhinitis only but who had a much lower prevalence of specific animal antigen skin prick positivity (8 out of 33 ). The third group comprised the remainder of the population, having no evidence of laboratory animal allergy. No one in this last group had positive skin prick tests to specific LAA antigens.

\section{Results}

The basic numerical data (table 1) were examined in terms of allergic disease to provide sensitivity, specificity, and predictive values for the different concepts of atopy (table 2).

Atopy defined by skin prick tests with common allergens was a sensitive $(80 \%)$ and quite specific $(82 \%)$ test for LAA asthma. Atopy defined by personal or family history was less discriminant. For LAA rhinitis all three definitions of atopy were insensitive (24-39\%). Even for skin prick test atopy, the predictive value of atopy for disease was low $(34 \%$ for LAA asthma, $23 \%$ for LAA rhinitis) and only $75 \%$ of non-atopics were without symptoms. Of those people classified as atopic by personal history, $65 \%$ would have been so classified by family history. Similarly for atopy classified by personal history as against skin prick test and atopy classified by family history as against skin prick test, the percentages were $72 \%$ an $\bar{b}$ $64 \%$ respectively. This is low for supposedly identicat parameters.

Pre-employment data on skin prick reactivity to common allergens was available in 46 of the 146 indion? viduals in the study (32\%). There was no evidences that these 46 were in any way an unrepresentative sample of the population. The atopic status of indies viduals had not altered between pre-employmen $\mathbb{D}$ examination and the period of the survey (mean 2.6 years, range 1-6). The theoretical consideration that the development of LAA might itself alter atopic sta? tus is therefore unlikely in this particular population but cannot be completely ruled out. Six people were్ skin test positive to cat fur, three to dog, and one to horse hair. Of these, only one, who responded to cat, dog, and horse, was not also responsive to grass or house dust mite. The exclusion of cat fur in the skin prick definition of atopy therefore had an insignificant effect on the number defined by thato criterion.

\section{Discussion}

The conceptual value and ubiquity of the idea on atopy has served to conceal its ambiguities. Many occupational physicians consider the three differento concepts of atopy we tested as synonymous, yet \&up study shows that they are not. Our evaluation of these concepts of atopy has identified three substantie different, albeit overlapping, populations. The in ${ }_{0} \mathrm{r}=$ ence we have drawn from this finding is that grea

Table 1 Concepts of atopy: basic numerical data

\begin{tabular}{|c|c|c|c|c|c|}
\hline & & LAA asthma & $L A A$ rhinitis & No $L A A$ & Total \\
\hline $\begin{array}{l}\text { Atopy* defined by } \\
\text { personal history } \\
\text { Atopy defined by } \\
\text { family history } \\
\text { Atopy }{ }^{\star} \text { defined by skin prick } \\
\text { tests with common allergens }\end{array}$ & $\begin{array}{l}\text { Atopy + } \\
\text { Atopy - } \\
\text { Atopy + } \\
\text { Atopy - } \\
\text { Atopy + } \\
\text { Atopy - }\end{array}$ & $\begin{array}{r}8 \\
8 \\
7 \\
9 \\
12 \\
3\end{array}$ & $\begin{array}{r}9 \\
24 \\
13 \\
20 \\
8 \\
25\end{array}$ & $\begin{array}{l}18 \\
79 \\
32 \\
65 \\
15 \\
82\end{array}$ & $+^{+14 *}$ \\
\hline
\end{tabular}

Table 2 Concepts of atopy: sensitivity, specificity, and positive predictive value (expressed as percentages) of atopy for LAA asthma and $L A A$ rhinitis, without asthma. Negative predictive value of absence of atopy for absence of $L A A$

\begin{tabular}{|c|c|c|c|c|c|c|c|}
\hline & \multicolumn{3}{|c|}{ LAA asthma } & \multicolumn{3}{|c|}{$L A A$ rhinitis } & \multirow{2}{*}{$\begin{array}{l}\text { No LAA } \\
\begin{array}{l}\text { Negative } \\
\text { predictive } \\
\text { value }\end{array}\end{array}$} \\
\hline & Sensitivity & Specificity & $\begin{array}{l}\text { Positive } \\
\text { predictive } \\
\text { value }\end{array}$ & Sensitivity & Specificity & $\begin{array}{l}\text { Positive } \\
\text { predictive } \\
\text { value }\end{array}$ & \\
\hline \multirow{2}{*}{$\begin{array}{l}\text { Personal history } \\
\text { Family history } \\
\text { Skin prick tests with } \\
\text { common allergens. }\end{array}$} & $\begin{array}{l}50 \\
44\end{array}$ & $\begin{array}{l}79 \\
65\end{array}$ & $\begin{array}{l}23 \\
13\end{array}$ & $\begin{array}{l}27 \\
39\end{array}$ & $\begin{array}{l}77 \\
65\end{array}$ & $\begin{array}{l}26 \\
25\end{array}$ & $\begin{array}{l}71 \\
69\end{array}$ \\
\hline & 80 & 82 & 34 & 24 & 76 & 23 & 75 \\
\hline
\end{tabular}




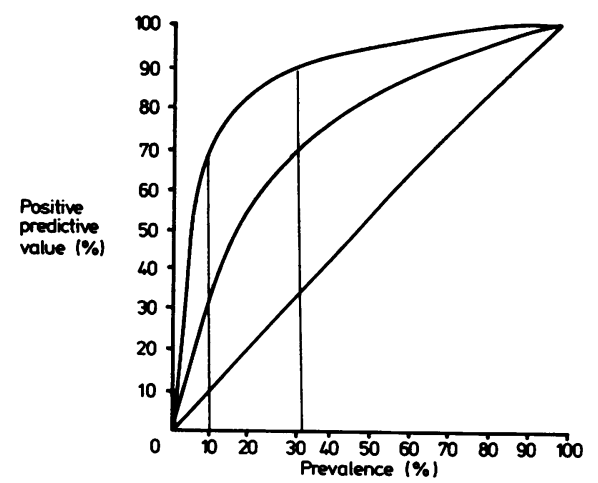

Predictive value of atopy at worst and best levels of sensitivity and specificity found in this study (bottom = sensitivity 39\%, specificity $65 \%$; middle = sensitivity $80 \%$, specificity $82 \%$; top $=$ sensitivity $95 \%$, specificity $95 \%$; last drawn for illustrative purposes only). Intercepts at study prevalence rates of $L A A(33 \%)$ and asthma $(10 \%)$.

caution must be exercised in the way that these concepts are used as discriminants or predictors of allergy.

In prevalence studies of occupational allergic disease the issue of atopy has usually been discussed only with regard to its sensitivity as a marker of various occupational allergic states. In some cases there has been no positive association at all, as with epoxy adhesives, azodicarbonamide, and piperazine. ${ }^{267}$ In other cases, such as animal allergies, ${ }^{3-5}$ some degree of association with atopy has been noted. These findings may be used to infer two main types of conclusion relating to specific immune mechanisms on the one hand and to predictive hypotheses on the other. It is the latter with which we are concerned here for the traditional, popular, and seldom denied inference from positive associations is that sensitivity and predictive value are directly linked. This is not necessarily so. To complete an assessment of such results the prevalence of the condition must be considered as well as the sensitivity and specificity of the screening test. $^{8}$

The relation between positive predictive value and prevalence is derived from the equation

$$
\mathrm{PV}=\frac{1}{1+\frac{(1-\mathrm{Sp})(1-\mathrm{P})}{\mathrm{P} \cdot \mathrm{Se}}}
$$

(where $P V=$ positive predictive value, $P=$ prevalence, $\mathrm{Se}=$ sensitivity, and $\mathrm{Sp}=$ specificity). From this formula a series of curves may be drawn for different combinations of sensitivity and specificity. For atopy related to LAA, the figure shows the curves for the best and worst sensitivity/specificity combina- tions in this study. The curve for $95 \%$ sensitivity and specificity is also drawn for illustrative purposes. The results of several studies have placed the prevalence of LAA in the range $11-33 \%$ with asthma accounting for between $25 \%$ and $33 \%$ of all disease. ${ }^{45-12}$ In the particular population considered in this study the prevalence of LAA was $33 \%$ with asthma at $10 \%$. The prevalence intercepts for these findings have been presented in the figure. They show clearly the shortcomings of any of the concepts of atopy as indicators of disease. For asthma, perhaps the most serious manifestation of LAA, a sensitivity and specificity of about $95 \%$ would be necessary to justify the use of atopy as a pre-employment screen in order to eliminate a simple majority of potential cases correctly.

Comparing the three concepts of atopy, we have shown that personal history and skin prick test results have statistically significant associations with LAA asthma but not with rhinitis: the best association is with atopy defined by skin prick tests with common allergens. Although we have shown that atopy is not a convincing marker of an individual's risk of developing LAA, the association shown does serve to indicate increased relative risk, at least for asthma. It seems reasonable that, whereas these relative risks should not be used as job discriminants, they may be used positively to give atopic individuals an informed view of their chances of developing LAA if they take up a job in exposure. Additionally, atopy may be used as an indication for more frequent or more searching monitoring in periodic medical surveillance.

The screening out of atopic individuals (by whatever criteria) from work in certain occupations remains a widespread occupational health practice. Our findings support the views put forward by Cockcroft $e t a l^{4}{ }^{13}$ and Newman Taylor ${ }^{14}$ whose studies in laboratory animal workers, despite some methodological differences, reached essentially the same conclusion. This was that the practice of excluding people found to be atopic at pre-employment medical examinations from work with laboratory animals should be abandoned. Though unlikely on present evidence, some forms of occupational asthma may possibly be more closely associated with atopy than is LAA asthma. In this situation, particularly in workplaces with a high rate of occupational asthma, such exclusion might be justified.

We thank M T Stevens for statistical advice and Mrs I Ball for secretarial work.

\section{References}

1 Keskinen $\mathbf{H}$, Alanko $\mathrm{K}$, Saarinen $\mathrm{L}$. Occupational asthma in Finland. Clin Allergy 1978;8:569-79.

2 Meadway J. Asthma and atopy in workers with an epoxy adhesive. Br J Dis Chest 1980;745:149-54. 
3 Burge PS, Edge G, O'Brien IM, Harries MG, Hawkins R, Pepys J. Occupational asthma in a research centre breeding locusts. Clin Allergy 1980;10:355-63.

4 Cockcroft A, McCarthy P, Edwards J, Andersson N. Allergy in laboratory animal workers. Lancet $1981 ; \mathrm{i}: 827-30$.

5 Slovak AJM, Hill RN. Laboratory animal allergy: a clinical survey of an exposed population. Br J Ind Med 1981;38:38-41.

6 Slovak AJM. Occupational asthma due to a plastics blowing agent: azodicarbonamide. Thorax 1981;36:906-9.

7 Hagmar L, Bellander T, Bergoo B, Simonsson BG. Piperazine induced occupational asthma. J Occup Med 1982;24:193-5.

8 Barker DGP, Rose G. Screening. In: Epidemiology in medical practice. Edinburgh: Churchill Livingstone, 1984:122-30.

9 Lutsky I, Neuman I. Laboratory animal dander allergy. 1. An occupational disease. Ann Allergy 1975;35:201-6.

그

10 Davies GE, McArdle LA. Allergy to laboratory animals: a survey by questionnaire. Int Arch Allergy Appl Immunol 1981;64: 302-6.

11 Lincoln TA, Bolton NE, Garrett AS, Jr. Occupational allergy to animal dander and sera. J Occup Med 1974;16:465-8.

12 Gross NJ. Allergy to laboratory animals: epidemiological, clinicato and physiological aspects, and a trial of cromolyn in its management. J Allergy Clin Immunol 1980;66:158-63.

13 Cockcroft A, Edwards J, McCarthy P. The role of preemployment allergy screening in animal workers. Eur J Respir Dis (suppl) 1981;113,62:42-3.

14 Newman Taylor AJ. Laboratory animal allergy. Eur J Respir Dis (suppl) 1982;63:60-4. 